\title{
Corona virus disease 2019: hysteresis effect of chest CT and the correlation of its severity with lymphocyte count in peripheral blood
}

\section{Kui Li (D 42131642@qq.com )}

Ankang Central Hospital https://orcid.org/0000-0002-5684-3918

\section{Wei Wang}

Ankang Central Hospital

Chang-Wu Zhao

Suixian People's Hospital

Lei Wu

Zhushan People`s Hospital

Ya-Nan Zhu

Ankang Central Hospital

Ren-Yu Ran

Ankang Central Hospital

Tao Li

Ankang Central Hospital

Zi-Cheng Jiang

Ankang Central Hospital

\section{Research}

Keywords: Coronavirus infections, tomography, X-ray computed, lymphocytes, hysteresis

Posted Date: April 2nd, 2020

DOI: https://doi.org/10.21203/rs.3.rs-20715/v1

License: (1) (1) This work is licensed under a Creative Commons Attribution 4.0 International License. Read Full License 


\section{Abstract}

Background Chest computed tomography (CT) has been accepted to provide reference for the diagnose and assessment the severity of Corona Virus Disease 2019 (COVID-19). Decrease in the counts of lymphocyte and leukocyte is used as the diagnostic indicator of suspected COVID-19 cases. However, there is few study on exploring the hysteresis of chest CT changes and the predictive role of lymphocyte count in peripheral blood before treatment in the severity of the disease.

Methods A retrospective analysis was carried out focusing on the data of patients tested to be positive for RNA nucleic acid test of SARS-CoV-2 with nasopharyngeal swabs in 4 hospitals. An independent assessment was performed by one clinician using the DEXIN FACT Workstation Analysis System, and the assessment results were reviewed by another clinician. Furthermore, the mean hysteresis time was calculated according to the median time from progression to the most serious situation to improvement of chest CT in patients after fever relief. The optimal scaling regression analysis was performed by including variables with statistical significance in univariate analysis. In addition, a multivariate regression model was established to investigate the relationship of the percentage of lesion/total lung volume with lymphocyte and other variables.

Results In the included 166 patients with COVID-19, the average value of the most serious percentage of lesion/total lung volume was 6.62, of which 90 patients with fever had an average hysteresis time of 4.5 days after symptom relief, with a similar trend observed in those without fever. Multivariate analysis revealed that lymphocyte count in peripheral blood and transcutaneous oxygen saturation decreased with the increase of the percentage of lesion/total lung volume. Meanwhile, age, fever and C-reactive protein exhibited no such effect in the established model.

Conclusions There is a hysteresis effect in the improvement of chest CT image in relative to fever relief in patients with COVID-19. Besides, the percentage of lesion/total lung volume of chest CT correlates negatively with lymphocyte count in peripheral blood and transcutaneous oxygen saturation. Findings in our study may contribute to understanding the disease status of patients with COVID-19 and grasping the opportunity of treatment by clinicians.

\section{Background}

Corona Virus Disease 2019 (COVID-19) is featured by strong infectivity, rapid development, and high incidence in Spring and Autumn, showing an epidemic trend in the world recently. With a high definition, computed tomography (CT) facilitates the display of ground glass-like shadows and foci in the overlapped area behind the heart for COVID-19 patients[1]. Despite limitations in qualitative diagnosis and quantification of lesions, CT is still the most widely used tool to diagnose and assess diseases worldwide. The weight of CT reached $41.67 \%(5 / 12)$ when it was used to evaluate the severity of COVID$19[2,3,4]$. 
In general, imaging severity of diseases can be graded by estimating the range of "abnormal" lung field. In the past, Seaton et al. [5, 6] described an anatomical site-based classification, besides, Ralph et al. [7] and Pan et al. [8] in the later stage proposed an evaluation method of using integral. These methods, however, are not only lack of accuracy, but also mainly used in chronic infectious diseases. With the development of medical imaging, quantitative CT analysis technology has been used in clinic in recent decades [9], mainly for the evaluation of pulmonary nodules. It will be totally a new perspective to apply CT to COVID-19, an acute infectious disease. It still requires further exploration on how to recognize the correlation between the degree of quantitative computerized image changes and clinical indicators. Simultaneously, it was found in our clinical practice that the lesion of chest CT was still progressing in some patients with fever relief. When would the relative hysteresis period of imaging end? It dose confuse our understanding of the disease clinically.

With respect to the above, the purpose of this study is to determine the hysteresis time of CT images in subjects with fever and compare the change trend of quantitative CT parameters with that of subjects without fever; and to clarify relevant factors affecting the percentage of lesion/total lung volume in patients with COVID-19.

\section{Methods}

\section{Study sites and patients}

The objects of study were 170 patients from 4 hospitals in 2 provinces of China from January 2020 to March 2020. According to the COVID-19 Diagnosis and Treatment Plan issued by the National Health Commission, patients were provided with antiviral treatment of interferon-a combined with Lopinavir/Ritonavir or Arbidol, chest CT scan every 3-5 days, sampling of nasopharynx swabs and routine blood examination (routine blood test, liver function, etc.). All enrolled patients were detected to have positive nucleic acid test results for severe acute respiratory syndrome coronavirus (SARS-CoV)-2 by real-time fluorescent RT-PCR of nasopharyngeal swabs. During the treatment period, patients were excluded for those $<18$ years old, with positive HIV antibody, and dead within one week after diagnosis.

\section{Percentage of lesion/total lung volume}

Chest CT images were scanned by an imaging technician according to the unified parameters (see Additional file 1). The imaging technician was responsible for the immediate assessment of the "readability" of the image and re-scanning of the unqualified image. The original data of collected images was then imported into the "Digital Lung" Pneumonia Quantitative Software (DEXIN FACT Workstation Analysis System) in a format of Digital Imaging and Communications in Medicine (DICOM), of which the software has been verified [10]. Pulmonary lesions of COVID-19 patients were automatically segmented, extracted and quantified. Subsequently, anther manual identification (especially ground glass-like shadows), segmentation and deletion of the lesion was carried out according to the preset inclusion and exclusion criteria (Table 1). Another doctor was involved to review the results carefully. Besides, a third senior doctor blinded with the assessment was invited to make the final determination in the case of 
inconsistent lesion judgment. The volume of the whole lung $(\mathrm{ml})$ and that of the lesion after manual correction $(\mathrm{ml})$ were automatically calculated by the system to obtain the percentage of the lesion/total lung volume. Finally, following repeated chest CT examination, the maximum value of the percentage of lesion/total lung volume was selected for univariate and multivariate analysis.

Table 1

Inclusion and exclusion criteria in the diagnosis of lesions

Inclusion Exclusion

Small patchy shadow and stromal changes

Ground glass-like shadow Infiltrative shadow

Pulmonary consolidation

Pleural effusion

Old lesions caused by previous underlying diseases

Artifacts at the junction of lung and chest wall, mediastinum and septal muscle

Pulmonary vascular shadow

Calcified lesion

Images before the onset of the disease or over 4 weeks after admission

\section{Virology and clinical data}

Nasopharynx swabs and demographic data were collected in all patients after admission. The sampled nasopharynx swabs shall be stored at $4{ }^{\circ} \mathrm{C}$ and sent to the laboratory of the Municipal Center for Disease Control and Prevention for testing within 4 hours. Corresponding procedures were carried out in accordance with the "Measures for the Management of Biological Safety Environment of Pathogenic Microorganisms Laboratory" and "Provisions on the Management of the Transportation of Pathogenic Microorganisms (Viruses) or Samples that Can Infect Human Beings" (Decree No.45 of Ministry of Health, P.R.China) [11]. It could be determined to be positive if the test results met the following requirements: (1) patients with simultaneous positive detection of ORF1ab and N gene; and (2) patients retested to have positive detection of ORF1 $\mathrm{ab}$ or $\mathrm{N}$ gene by nucleic acid retest of the re-extracted original sample for those with positive ORF1ab or $\mathrm{N}$ gene in the first-time detection.

Chest CT hysteresis time: on the basis of calculation from the first day of admission, it was defined as the average duration (days) of fever by subtracting the average duration of fever after admission from the median time of lesion/total lung volume percentage reduction $\geq 10 \%$ compared with the previous time in subjects with fever (nursing record of body temperature $\geq 37.3^{\circ} \mathrm{C}$ ). Cough and asthma symptoms were not included in this analysis since the two symptoms had no clear time line for relief, which might hence affect the accurate quantitative results. Data related to routine blood test, C-reactive protein (CRP), albumin and transcutaneous oxygen saturation (without oxygen inhalation) subjected to the first test results of patients after admission. As part of the clinical data, the inpatients were tested for HIV, in combination of collecting medical history of diabetes, hypertension, etc.

\section{Statistical analysis}

Multivariate analysis of variance was used to compare the percentage of lesion/total lung volume in subjects with and those without fever at different times. Univariate analysis for baseline characteristics 
(age, gender, body mass index, primary/secondary cases, leukocytes, lymphocytes and presence of underlying diseases) and the percentage of lesion/total lung volume were analyzed by Mann-Whitney $\mathrm{U}$ test, Kruskal-Wallis $\mathrm{H}$ test (categorical variables) and Spearman correlation analysis (measurement variables). The presence of collinearity was determined if the correlation coefficient of the two variables was $>0.8$ or the tolerance was $<0.1$ before data conversion. Series mean was used to replace the missing value. Finally, the variables with statistical significance in univariate analysis $(P<0.05)$ were involved for optimal scaling regression analysis. SPSS 22.0 (IBM Corp., Armonk, NY, USA) and GraphPad Prism 8.0.2 (GraphPad Software, La Jolla, CA, USA) were used for statistical analysis in this study.

\section{Results}

Out of 170 confirmed patients with COVID-19 in 4 hospitals, 4 cases were excluded, and 166 were finally included in the study (Fig. 1). Of the enrolled 166 subjects, the average age was $43.05 \pm 13.36$ years old, with $52.41 \%(87 / 166)$ males. After the quality examination by three doctors, 617 images were included in the evaluation, of which 13 cases were found to have no pathological changes in the lung. The completion rates of examination within 1-2 days, 3-6 days, 7-10 days, 11-15 days and 16-21 days were $100 \%, 78.31 \%, 81.93 \%, 74.10 \%$ and $37.35 \%$, respectively.

\section{Changes of DICOM analysis parameters at different times}

Table 2 shows the changes of parameters such as total lung volume and lesion volume at different times, in which the percentage of lesion/total lung volume was the largest within 3-6 days after admission and tended to improve in 7-10 days. Figure 2 displays the change of representative case. Chest CT showed that the median percentage of lesion/total lung volume was 6.62 , with the interquartile range of between 3.59-10.25. 
Table 2

Changes of chest CT parameters in different time periods

\begin{tabular}{|c|c|c|c|c|c|}
\hline CT parameters & $\begin{array}{l}1-2 \text { days } \\
(N=160)\end{array}$ & $\begin{array}{l}3-6 \text { days } \\
(N=129)\end{array}$ & $\begin{array}{l}7-10 \text { days } \\
(\mathrm{N}=134)\end{array}$ & $\begin{array}{l}11-15 \text { days } \\
(\mathrm{N}=119)\end{array}$ & $\begin{array}{l}16-21 \text { days } \\
(\mathrm{N}=62)\end{array}$ \\
\hline Missing Data, n (\%) & $0(0.00)$ & 36 (21.69) & $30(18.07)$ & $43(25.90)$ & $104(62.65)$ \\
\hline $\begin{array}{l}\text { Chest CT showed no } \\
\text { lesions, } \mathrm{n}(\%)\end{array}$ & $6(3.61)$ & $1(0.60)$ & $2(1.20)$ & $4(2.41)$ & $0(0.00)$ \\
\hline $\begin{array}{l}\text { Total lung volume, } \\
\mathrm{mL} \text {, median (IQR) }\end{array}$ & $\begin{array}{l}3805.00 \\
(3243.72- \\
4645.23)\end{array}$ & $\begin{array}{l}3617.17 \\
(3114.68- \\
4546.73)\end{array}$ & $\begin{array}{l}3968.21 \\
(3431.38- \\
4742.65)\end{array}$ & $\begin{array}{l}3919.04 \\
(3369.59- \\
4365.60)\end{array}$ & $\begin{array}{l}3875.69 \\
(3395.52- \\
4390.86)\end{array}$ \\
\hline $\begin{array}{l}\text { Lesion volume, mL, } \\
\text { median (IQR) }\end{array}$ & $\begin{array}{l}221.83 \\
(107.68- \\
346.77)\end{array}$ & $\begin{array}{l}250.24 \\
(139.37- \\
377.27)\end{array}$ & $\begin{array}{l}170.54 \\
(77.30- \\
264.91)\end{array}$ & $\begin{array}{l}138.97 \\
(72.74- \\
195.48)\end{array}$ & $\begin{array}{l}56.51 \\
(42.67- \\
70.46)\end{array}$ \\
\hline $\begin{array}{l}\text { Average CT density of } \\
\text { lesions, HU, median } \\
\text { [IQR] }\end{array}$ & $\begin{array}{l}-488.24 \\
{[(-408.01)-} \\
(-589.62)]\end{array}$ & $\begin{array}{l}-470.78 \\
{[(-408.32)-} \\
(-545.97)]\end{array}$ & $\begin{array}{l}-501.84 \\
{[(-436.67)-} \\
(-583.66)]\end{array}$ & $\begin{array}{l}-464.55 \\
{[(-412.49)-} \\
(-553.44)]\end{array}$ & $\begin{array}{l}-492.41 \\
{[(-408.15)-} \\
(-578.40)]\end{array}$ \\
\hline $\begin{array}{l}\text { Lesion/total lung } \\
\text { volume, \%, median } \\
\text { (IQR) }\end{array}$ & $\begin{array}{l}5.51 \\
(3.20-9.67)\end{array}$ & $\begin{array}{l}6.65 \\
(3.76-10.71)\end{array}$ & $\begin{array}{l}4.18 \\
(2.11-7.38)\end{array}$ & $\begin{array}{l}3.43 \\
(1.63-5.58)\end{array}$ & $\begin{array}{l}1.51 \\
(1.13-1.79)\end{array}$ \\
\hline \multicolumn{2}{|l|}{$\begin{array}{l}\triangle \text { Lesion/total lung } \\
\text { volume, \%a }\end{array}$} & $20.69 \uparrow$ & $37.14 \downarrow$ & $17.94 \downarrow$ & $55.98 \downarrow$ \\
\hline \multicolumn{6}{|c|}{ 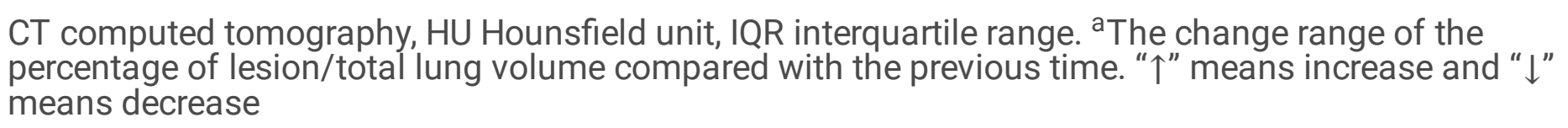 } \\
\hline
\end{tabular}

\section{Image hysteresis time of patients with fever}

The median disappearance time of fever was 3.5 (2.00-5.25) days in the 90 subjects with fever after admission. The first $\geq 10 \%$ decrease in the percentage of lesion/total lung volume compared with the previous time was in 7-10 days, with a median time of 8 days. Hence, the image hysteresis time of subjects with fever was measured to be 8.0-3.5 $=4.5$ days. Analysis of variance indicated that there was no difference in the change of the percentage of lesion/total lung volume in subjects with and those without fever and all subjects at different times $(F=1.839, P=0.161)$ (Fig. 3). Besides, there was obvious difference in the percentage of lesion/total lung volume at different times (all $P<0.001$ ), without the discovery of interaction between time and group (see Additional file 2).

\section{Influential factor of the percentage of lesion/total lung volume}


According to the results of univariate analysis, age, fever, absolute value of lymphocyte, CRP and transcutaneous oxygen saturation were significantly related to the percentage of lesion/total lung volume (all $\mathrm{P}<0.05$ ) (Tables 3 and 4). These 5 variables were thus included in the multivariate analysis. Corresponding correlation coefficients were $<0.8$ (age and lymphocyte count were the largest dependent variable with a coefficient of -0.348 ), and there was no variable with the tolerance $<0.1$. The results showed that the adjusted $\mathrm{R}^{2}$ was 0.250 , indicating the existence of statistical significance of the established regression model $(F=10.675, P<0.001)$. Meanwhile, lymphocyte count and transcutaneous oxygen saturation were independent risk factors for the percentage of lesion/total lung volume (all $\mathrm{P}<$ 0.05 ) (Table 5), with the importance of $0.519,0.388$ and the sum of the importance of 0.907 , respectively (see Additional file 3). 
Table 3

Univariate analysis of the percentage of lesion/total lung volume (nominal and ordinal variables)

\begin{tabular}{|c|c|c|c|c|}
\hline Variable & $\mathbf{N}(\%)$ & $\begin{array}{l}\text { lesion/total lung volume, \%, } \\
\text { median (IQR) }\end{array}$ & Test value & $p$ value \\
\hline Total & $166(100.00)$ & $6.68(3.91-10.43)$ & & \\
\hline Sex & & & $Z=3410.00$ & 0.932 \\
\hline Female & 79 (47.59) & $6.41(3.91-10.26)$ & & \\
\hline Male & $87(52.41)$ & $6.68(3.25-10.25)$ & & \\
\hline \multicolumn{5}{|l|}{ Case type } \\
\hline First-generation $^{a}$ & $85(51.20)$ & $6.07(3.25-8.89)$ & $\chi^{2}=4.707$ & 0.095 \\
\hline Second-generation ${ }^{\mathrm{b}}$ & $46(27.71)$ & $8.67(4.01-11.86)$ & & \\
\hline Inclassificaceis ${ }^{c}$ & $35(21.09)$ & $6.67(4.61-9.68)$ & & \\
\hline Fever & & & $Z=4082.00$ & 0.032 \\
\hline No & 76 (45.78) & $5.83(3.25-9.06)$ & & \\
\hline Yes & $90(54.22)$ & $7.01(4.26-10.85)$ & & \\
\hline Basic disease & & & $Z=2319.00$ & 0.474 \\
\hline No & $134(80.72)$ & $6.65(3.46-10.12)$ & & \\
\hline Yes & $32(19.28)$ & $6.42(4.03-11.06)$ & & \\
\hline Cardiovascular disease $^{d}$ & 19 (11.45) & & & \\
\hline Diabetes mellitus $^{d}$ & $9(5.42)$ & & & \\
\hline Kidney disease & $3(1.81)$ & & & \\
\hline Tuberculosis & $2(1.20)$ & & & \\
\hline Other & $3(1.81)$ & & & \\
\hline \multicolumn{5}{|c|}{$\begin{array}{l}\text { IQR interquartile range. Note: Z value obtained by Mann-Whitney } \mathrm{U} \text { test, and } 2 \text { was Kruskal-Wallis } \mathrm{H} \\
\text { test. } \\
{ }^{\text {a }} \text { Refers to the Hubei traverl/residence hsitory, }{ }^{\text {b }} \text { Refers to the contact with people from Hubei, }{ }^{\text {CRefers }} \\
\text { to no traceable exposure history to Hubei, }{ }^{\mathrm{d}} \text { Co-existence of these two diseases in } 4 \text { cases, }{ }^{e} \text { One case } \\
\text { of chronic hepatitis B, cirrhosis and rectal cancer after ostomy, respectively }\end{array}$} \\
\hline
\end{tabular}


Table 4

Univariate analysis of the percentage of lesion/total lung volume (numeric variables)

\begin{tabular}{|c|c|c|c|c|c|}
\hline \multirow[t]{2}{*}{ Variable } & \multicolumn{2}{|c|}{ Missing data } & \multirow{2}{*}{$\begin{array}{l}\text { Median (IQR) } \\
\text { or } \\
\text { Please click here to download the } \\
\text { original image file } \\
\text { Click here to Correct } \\
\pm \mathrm{s}^{\mathrm{a}}\end{array}$} & \multirow[t]{2}{*}{$\mathbf{R}$} & \multirow{2}{*}{$\begin{array}{l}p \\
\text { value }\end{array}$} \\
\hline & $\mathbf{N}$ & (\%) & & & \\
\hline Age (years) & 0 & $(00.00)$ & $43.05 \pm 13.36$ & $0.182^{*}$ & 0.019 \\
\hline $\begin{array}{l}\text { Body-mass index } \\
\left(\mathrm{kg} / \mathrm{m}^{2}\right)\end{array}$ & 0 & $(00.00)$ & $22.74 \pm 2.57$ & -0.080 & 0.304 \\
\hline $\begin{array}{l}\text { White blood cell }(x \\
\left.10^{9} / \mathrm{L}\right)\end{array}$ & 5 & (3.01) & $4.93(3.87-6.11)$ & -0.065 & 0.411 \\
\hline $\begin{array}{l}\text { Absolute lymphocyte } \\
\left(\times 10^{9} / \mathrm{L}\right)\end{array}$ & 5 & $(3.01)$ & $1.21(0.92-1.46)$ & $-0.397 * \star$ & $\nabla 0.001$ \\
\hline $\begin{array}{l}\text { C-reactive protein } \\
(\mathrm{mg} / \mathrm{L})\end{array}$ & 16 & (9.64) & $10.00(6.72-26.15)$ & $0.178^{*}$ & 0.029 \\
\hline Albumin $(\mathrm{g} / \mathrm{L})$ & 0 & $(00.00)$ & $38.83 \pm 5.85$ & -0.137 & 0.078 \\
\hline TcSO2 (\%) & 0 & $(00.00)$ & $97.00(95.00-98.00)$ & $-0.259 * *$ & 0.001 \\
\hline
\end{tabular}

Table 5

Optimal scale regression analysis of the percentage of lesion/total lung volume

\begin{tabular}{|c|c|c|c|c|}
\hline Variable & Beta & $\begin{array}{l}\text { Standardized } \\
\text { coefficients std.error }\end{array}$ & $\mathbf{F}$ & $p$ value \\
\hline \multicolumn{5}{|l|}{ Fever } \\
\hline Without vs. with & 0.078 & 0.056 & 1.946 & 0.165 \\
\hline Age & 0.017 & 0.071 & 0.057 & 0.811 \\
\hline Absolute lymphocyte & -0.321 & 0.075 & 18.410 & $\otimes 0.001$ \\
\hline C-reactive protein & 0.047 & 0.069 & 0.461 & 0.498 \\
\hline TcSO2 & -0.286 & 0.070 & 16.875 & $\llbracket 0.001$ \\
\hline
\end{tabular}




\section{Correlation between the percentage of lesion/total lung volume and independent risk factors}

The independent risk factors and the percentage of lesion/total lung volume were converted by Rankit normal-distribution integral. Subsequent correlation analysis revealed that the percentage of lesion/total lung volume decreased with the increase of lymphocyte count in peripheral blood and transcutaneous oxygen saturation, showing moderate and mild correlation, respectively $(r=0.395, r=0.292)$ (Figs. 4 and $5)$.

\section{Discussion}

In our study, based on "Digital Lung" Pneumonia Automatic Detection/Quantitative System, quantitative detection indexes of COVID-19 patients were obtained by computer-aided detection and manual correction, including total lung volume, lesion volume, and average density of lesions. Among them, lesion volume is the most basic feature of lesions, which directly reflects the actual size of the lesion, total lung volume is the basic general description of whole lung in the patient, and density can help to judge the composition and nature of lesions. The percentage of lesion/total lung volume reflects the severity of the disease in part and in general.

According to the results of this study, $74.10 \%$ (123/166) of patients with COVID-19 reported fever, with the median time of fever of 5.0 (4.0-8.0) days before admission. After admission, $54.22 \%$ of the patients were confirmed to have fever, and the median time of remission was 3.5 (2.0-5.3) days. Furthermore, images of chest CT began to improve with an average hysteresis of 4.5 days after fever relief. It was 13 days when it was calculated since the onset of fever, which was similar to those reported by Jin et al [12] and Pan et al [8] that the radiological manifestation of chest CT entered the dissipation stage at 2-3 weeks. Simultaneously, findings in our study suggest that: (1) clinical symptoms are still important clues for early assessment of the disease; and (2) the possibility of developing to severe lesions should be alerted if there is still progression in chest CT of patients beyond this median time.

Patients with fever had a higher percentage of lesion/total lung volume. It is speculated that fever attenuates the immune response of cytokines by inhibiting the expression of tumor necrosis factor-a at ribonucleic acid level [13], thus inhibiting the immune response of natural killer (NK) cells [14] and cytotoxic T lymphocytes (CTL) [15], resulting in a higher risk of lesion spread. The present study further analyzed the relationship between fever and lymphocyte, and it was found that lymphocyte count was lower in patients with fever (Fig. 6).

In the subsequent univariate analysis, both age and CRP level showed positive correlation with the percentage of lesion/total lung volume, which was consistent with the higher intensive care unit admission rate [16] and more pulmonary consolidation [17] reported by Wang et al. Elevated CRP in patients with COVID-19 was revealed to be associated with acute lung injury $[18,19]$. However, age and CRP had little effect in this study, which were not statistically significant in the final multivariate analysis. 
In addition, no significant difference was discovered in the impact of travel or residence history of Hubei Province on the area of lesion, which was consistent with the domestic report [20]. Meanwhile, 19.28\% $(32 / 166)$ patients had underlying diseases, which was lower than that reported by Huang et al. [21]. It is possible that the elderly developed the disease in a pattern of family-centered rather than communitycentered onset in other regions outside Wuhan. It is thus not related to the elderly patients with more underlying diseases.

Peripheral blood lymphocytes include T, B, NK, CTL and other cells. NK cells play a crucial role in the first phase of immune response against infections, which is quite important in controlling the viral load of lung in the early stage of virus infection $[22,23,24]$. Studies have demonstrated that the severity of pulmonary lesions is positively correlated with the viral load in the body [19], while the latter one exhibits an intimate correlation with the decline of immune cells [25]. Therefore, the lymphocyte count reflects the degree of pulmonary lesions to a certain extent. In the sequential studies, it was found that the activation of CD4 and CD8 T cells was impaired in SARS-CoV infected patients [26, 27], and the decrease of T lymphocyte count was strongly correlated with the severity of lesion in the acute phase $[28,29]$. In our study, counts of lymphocyte in $37.95 \%(63 / 166)$ patients were lower than the lower limit of normal value $\left(1.1 \times 10^{9} / \mathrm{L}\right)$, which was close to the lymphocyte decline rate reported by Assiri et al. [30] in Middle East respiratory syndrome coronavirus (MERS-CoV). It suggests that lymphocyte count presents similar change in COVID-19 compared with that in SARS-CoV and MERS-CoV, which is an independent negative risk factor for the percentage of lesion/total lung volume. It may provide a strong scientific basis for early identification of severe patients.

Furthermore, oxygen saturation reflects the percentage of oxyhemoglobin in total hemoglobin. Its decrease suggests that the alveolar injury and the concomitant increase of cellular fibromyxoid exudates may further lead to the ventilatory disorder of patients [31], and the degree of decrease may indirectly reflect the degree of pathological changes. In this study, $16.27 \%(27 / 166)$ patients showed the oxygen saturation of $<95 \%$, which was different from $9.40 \%$ reported by Yang et al. [20]. It may be explained by the disunity of detection methods and oxygen inhalation.

The study still has certain limitations as described below. (1) A descriptive study was carried out only for the image hysteresis of chest CT, without further time series analysis on changes of body temperature and the percentage of lesion/total lung volume. (2) In this study, the area of lesion was the main criterion for lesion identification. Despite the presence of statistical significance regarding changes of CT value of lesions at different times (Friedman test, $\chi^{2}=179.412, \mathrm{P}<0.001$ ), CT value is not constant and can be changed with power supply, scanning parameters, temperature and adjacent tissues. Therefore, it is necessary to combine the actual situation for judgment in the application. (3) In 16-21 days, $62.65 \%$ $(104 / 166)$ of the patients were discharged without further chest CT scan for follow-up, showing a reduced representativeness during this period of time. Nevertheless and significantly, our study for the first time realizes the accurate quantitative analysis, dynamic evaluation and the exploration of its influencing factors for the lesion of COVID-19 patients, and provides a time node for the progress of the disease.

Page $11 / 21$ 


\section{Conclusions}

To sum up, our study suggests that the possibility of developing to severe lesions should be alerted if there is still progression in chest CT images of COVID-19 patients 4.5 days after fever relief. Meanwhile, on the basis of lymphocyte count in peripheral blood or transcutaneous oxygen saturation monitoring, real-time dynamic tracking of lesion changes in patients may contribute to understanding disease status of patients with COVID-19 and grasping the opportunity of treatment by clinicians.

\section{Abbreviations}

COVID-19:corona virus disease 2019; CRP:C-reactive protein; CT:computed tomography; CTL:cytotoxic T lymphocytes; DICOM:digital Imaging and communications in medicine; IQR:interquartile range; MERSCoV:Middle East respiratory syndrome coronavirus; NK:natural killer cells; R:Spearman`s rho correlation coefficient; SARS-CoV:severe acute respiratory syndrome coronavirus; TcSO2:transcutaneous saturation of oxygen.

\section{Declarations}

\section{Acknowledgments}

We thank all participants of the COVID-19 study, without whom this study would not have been possible, and the study clinicians and nursing staff, and all staff involved in the COVID-19 study at all of our study sites.

\section{Funding}

This study was supported by the Ankang City Science Foundation (No. AK2020-XG-11 and No. AK2020XG-01).

\section{Availability of data and materials}

The datasets used and/or analyzed during the current study are available from the corresponding author on reasonable request.

\section{Authors' contributions}

$\mathrm{KL}$ and Z-CJ designed the study, performed data analysis and data interpretation, and wrote the manuscript. WW, C-WZ and LW analyzed the chest CT. Y-NZ, R-YR and TL were instrumental in 


\section{Ethics approval and consent to participate}

This study was approved by the Ethics Committee of the Ankang Central Hospital (ECACH-2020002). The patient's informed written consent to analysis of their medical records was waived due to the retrospective nature of this study. No further permission from the hospital was required.

\section{Consent for publication}

Not applicable

\section{Competing interests}

The authors declare that they have no competing interests.

\section{Publisher's Note}

Springer Nature remains neutral with regard to jurisdictional claims in published maps and institutional affiliations.

\section{Author details}

${ }^{1}$ Department of Infectious Diseases, Ankang Central Hospital, 85 South Jinzhou Road, Ankang 725000, Shaanxi Province, China. ${ }^{2}$ Department of Infectious Diseases, Ankang Central Hospital, Hubei University of Medicine, 30 South Renmin Road, Shiyan 442000, Hubei Province, China. ${ }^{3}$ Department of Pediatric, Suixian People's Hospital, Suixian County, Suizhou 431500, Hubei Province, China. ${ }^{4}$ Department of Endocrinology, Zhushan People's Hospital, Zhushan County, Shiyan 442200, Hubei Province, China. ${ }^{5}$ The Medical Imaging Centre, Ankang Central Hospital, 85 South Jinzhou Road, Ankang, 725000, Shaanxi, China.

\section{References}

1. Yoshida Y, Kokubu A, Suzuki K, Kuribayashi H, Tsuta K, Matsuno Y, et al. Molecular markers and changes of computed tomography appearance in lung adenocarcinoma with ground-glass opacity. 
Jpn J Clin Oncol. 2007;37(12):907-12.

2. Nanshan Chen, Min Zhou, Xuan Dong, Jieming Qu, Fengyun Gong, Yang Han, et al. Epidemiological and Clinical Characteristics of 99 Cases of 2019 Novel Coronavirus Pneumonia in Wuhan, China: A Descriptive Study. Lancet. 2020;395 (10223): 507-13.

3. Pan Y, Guan H, Zhou S, Wang Y, Li Q, Zhu T, et al. Initial CT findings and temporal changes in patients with the novel coronavirus pneumonia (2019-nCoV): a study of 63 patients in Wuhan, China. Eur Radiol. 2020; doi: 10.1007/s00330-020-06731-x.

4. Zu ZY, Jiang MD, Xu PP, Chen W, Ni QQ, Lu GM, et al. Coronavirus Disease 2019 (COVID-19): A Perspective from China. Radiology. 2020; doi: 10.1148/radiol.2020200490.

5. Seaton, A. Crofton and Douglas's respiratory diseases (ed. Seaton, A.) 409-410 (Leitch, A. G. 1989).

6. National Tuberculosis and Respiratory Disease Association. Diagnostic Standards and Classification of Tuberculosis. New York: National Tuberculosis and Respiratory Disease Association; 1969. p. 94.

7. Ralph AP, Ardian M, Wiguna A, Maguire GP, Becker NG, Drogumuller G, et al. A simple, valid, numerical score for grading chest $\mathrm{x}$-ray severity in adult smear-positive pulmonary tuberculosis. Thorax. 2010;65(10):863-69.

8. Pan F, Ye T, Sun P, Gui S, Liang B, Li L, et al. Time Course of Lung Changes On Chest CT During Recovery From 2019 Novel Coronavirus (COVID-19) Pneumonia. Radiology. 2020; doi:10.1148/radiol.2020200370.

9. Vineet K Raghu, Wei Zhao, Jiantao Pu, Joseph K Leader, Renwei Wang, James Herman, et al. Feasibility of lung cancer prediction from low-dose CT scan and smoking factors using causal models. Thorax. 2019; 74(7): 643-9.

10. Gu S, Fuhrman C, Meng X, Siegfried JM, Gur D, Leader JK, et al. Computerized identification of airway wall in CT examinations using a 3D active surface evolution approach. Med Image Anal. 2013;17(3):283-96.

11. National Health Commission of the People's Republic of China. Provisions on the Management of the Transportation of Pathogenic Microorganisms (Viruses) or Samples that Can Infect Human Beings (Decree No.45 of Ministry of Health, P.R.China). 2005. http://www.nhc.gov.cn/qjjys/s3589/200804/081c1f4c9a934fda887c1534abb3dd94.shtml. Accessed 8 Mar 2020.

12. Jin $Y H$, Cai L, Cheng ZS, Cheng $H$, Deng T, Fan YP, et al. A rapid advice guideline for the diagnosis and treatment of 2019 novel coronavirus (2019-nCoV) infected pneumonia (standard version). Mil Med Res. 2020;7(1):4.

13. Singh IS, He JR, Calderwood S, Hasday JD. A high affınity HSF-1 binding site in the 5'-untranslated region of the murine tumor necrosis factor-alpha gene is a transcriptional repressor. J Biol Chem. 2002;277(7):4981-8.

14. Azocar J, Yunis EJ, Essex M. Sensitivity of human natural killer cells to hyperthermia. Lancet. 1982;1(8262):16-7. 
15. Harris JW, Meneses JJ. Effects of hyperthermia on the production and activity of primary and secondary cytolytic T-lymphocytes in vitro. Cancer Res. 1978;38(4):1120-6.

16. Wang D, Hu B, Hu C, Zhu F, Liu X, Zhang J, et al. Clinical Characteristics of 138 Hospitalized Patients With 2019 Novel Coronavirus-Infected Pneumonia in Wuhan, China. JAMA. 2020: e201585.

17. Song F, Shi N, Shan F, Zhang Z, Shen J, Lu H, et al. Emerging 2019 Novel Coronavirus (2019-nCoV) Pneumonia. Radiology. 2020;295(1):210-7.

18. Li LQ, Huang T, Wang YQ, Wang ZP, Liang Y, Huang TB, et al. 2019 novel coronavirus patients' clinical characteristics, discharge rate and fatality rate of meta-analysis. J Med Virol. 2020;doi: 10.1002/jmv.25757.

19. Liu Y, Yang Y, Zhang C, Huang F, Wang F, Yuan J, et al. Clinical and biochemical indexes from 2019nCoV infected patients linked to viral loads and lung injury. Sci China Life Sci. 2020;63(3):364-74.

20. Yang W, Cao Q, Qin L, Wang X, Cheng Z, Pan A, et al. Clinical characteristics and imaging manifestations of the 2019 novel coronavirus disease (COVID-19):A multi-center study in Wenzhou city, Zhejiang, China. J Infect. 2020:S0163-4453(20)30099-2.

21. Huang C, Wang Y, Li X, Ren L, Zhao J, Hu Y, et al. Clinical features of patients infected with 2019 novel coronavirus in Wuhan, China. Lancet. 2020;395(10223):497-506.

22. Nogusa S, Ritz BW, Kassim SH, Jennings SR, Gardner EM. Characterization of age-related changes in natural killer cells during primary influenza infection in mice. Mech Ageing Dev. 2008;129(4):223-30.

23. Denney L, Aitken C, Li CK, Wilson-Davies E, Kok WL, Clelland C, et al. Reduction of natural killer but not effector CD8 T lymphocytes in three consecutive cases of severe/lethal H1N1/09 influenza A virus infection. PLoS One. 2010;5(5):e10675.

24. Mao H, Liu Y, Sia SF, Peiris JSM, Lau YL, Tu W. Avian influenza virus directly infects human natural killer cells and inhibits cell activity. Virol Sin. 2017;32(2):122-9.

25. Peiris JS, Lai ST, Poon LL, Guan Y, Yam LY, Lim W, et al. Coronavirus as a possible cause of severe acute respiratory syndrome. Lancet. 2003;361(9366):1319-25.

26. Cai $C$, Zeng $X, O u$ AH, Huang $Y$, Zhang $X$. Study on $T$ cell subsets and their activated molecules from the convalescent SARS patients during two follow-up surveys. Xi bao yu fen zi mian yi xue za zhi = Chinese journal of cellular and molecular immunology. 2004;20:322-324.

27. Yu XY, Zhang YC, Han CW, Wang P, Xue XJ, Cong YL. Change of T lymphocyte and its activated subsets in SARS patients. Zhongguo yi xue ke xue yuan xue bao. Acta Academiae Medicinae Sinicae. 2003;25:542-6.

28. Li T, Qiu Z, Zhang L, Han Y, He W, Liu Z, et al. Significant changes of peripheral T lymphocyte subsets in patients with severe acute respiratory syndrome. J Infect Dis. 2004;189(4):648-51.

29. Li T, Qiu Z, Han Y, Wang Z, Fan H, Lu W, et ao. Rapid loss of both CD4+ and CD8+ T lymphocyte subsets during the acute phase of severe acute respiratory syndrome. Chinese medical journal. 2003;116:985-7. 
30. Assiri A, Al-Tawfiq JA, Al-Rabeeah AA, Al-Rabiah FA, Al-Hajjar S, Al-Barrak A, et al. Epidemiological, demographic, and clinical characteristics of 47 cases of Middle East respiratory syndrome coronavirus disease from Saudi Arabia: a descriptive study. The Lancet infectious diseases. 2013;13:752-61.

31. Xu Z, Shi L, Wang Y, Zhang J, Huang L, Zhang C, et al. Pathological findings of COVID-19 associated with acute respiratory distress syndrome. Lancet Respir Med. 2020:S2213-2600(20)30076-X.

\section{Figures}

\section{Laboratory Data for Inclusion: Patients with COVID-19}

(Suixian, $N=94$; Zhushan, $N=35$;

$$
\text { Ankang, } \mathrm{N}=26 \text {; Xi'an, } \mathrm{N}=15 \text { ) }
$$

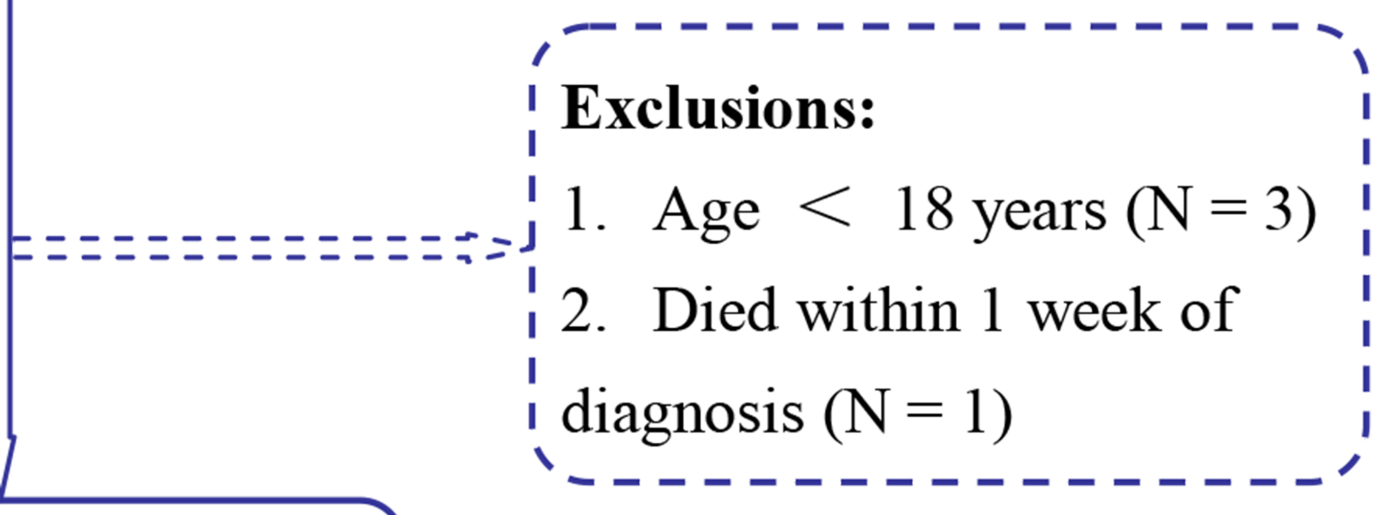

\section{Final Inclusion:}

Patients with COVID-19

$$
(\mathrm{N}=166)
$$

Figure 1

Flowchart of the study population. COVID-19 corona virus disease 2019 

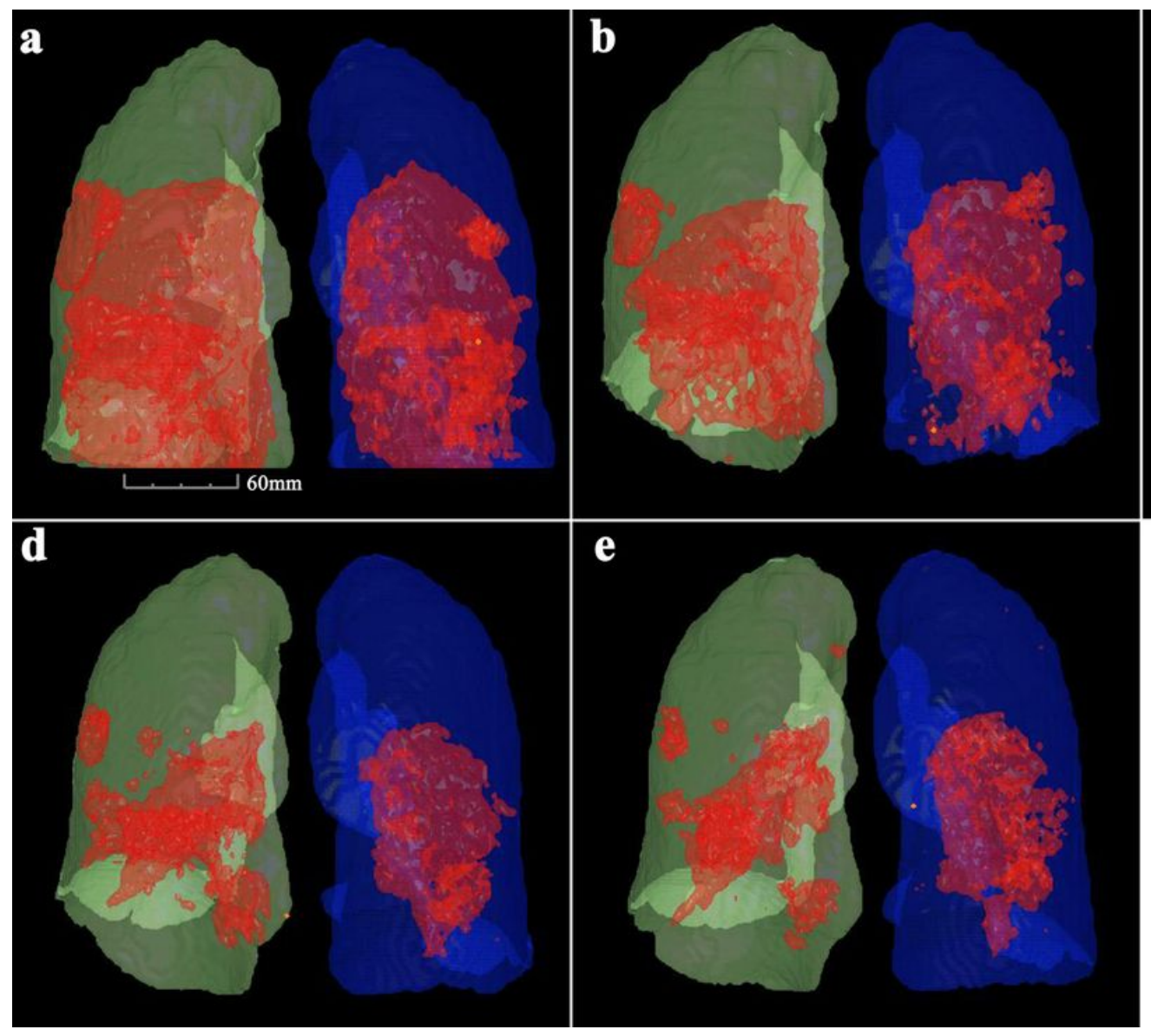

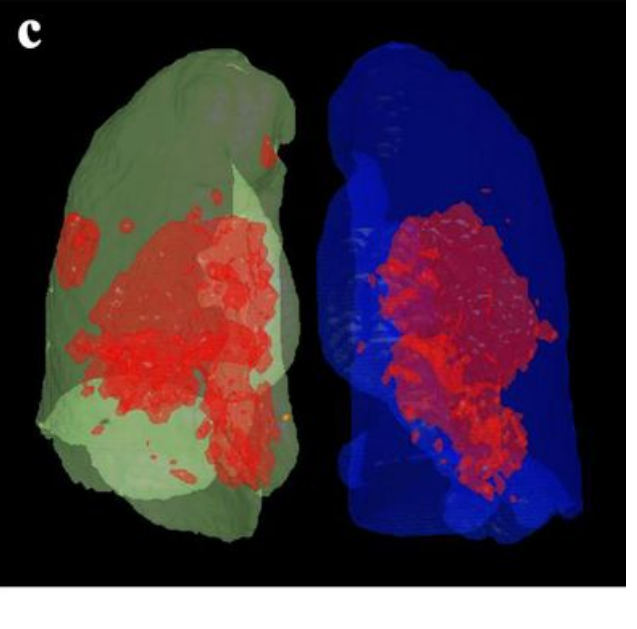

\begin{tabular}{cccc}
\hline $\begin{array}{c}\text { Panel } \\
\text { marks }\end{array}$ & $\begin{array}{c}\text { Total lung } \\
\text { volume } \\
(\mathrm{mL})\end{array}$ & $\begin{array}{c}\text { Lesion } \\
\text { volume } \\
(\mathrm{mL})\end{array}$ & $\begin{array}{c}\text { Lesion/total } \\
\text { lung volume } \\
(\%)\end{array}$ \\
\hline a & 3301.97 & 988.40 & 23.98 \\
b & 3060.61 & 368.26 & 12.03 \\
c & 3619.67 & 329.89 & 9.11 \\
d & 3984.63 & 268.66 & 6.74 \\
e & 4261.23 & 207.92 & 4.88 \\
\hline
\end{tabular}

\section{Figure 2}

Changes in lesions at different times in COVID-19. A male patient aged 37 years old had low fever (maximum body temperature of $37.8^{\circ} \mathrm{C}$ ) and dry cough for 11 days, with the initial diagnosis of type 2 diabetes. Chest CT examination: scattered flocculent, patchy and slightly high-density shadows with unclear boundary in both lungs. Red area represents the lesion volume, Green and blue represent the normal lung volumes of the right and left lungs, respectively. $a, b, c, d$ and e were the images on the 2nd, 6th, 10th, 15th and 21 st day after treatment, respectively 


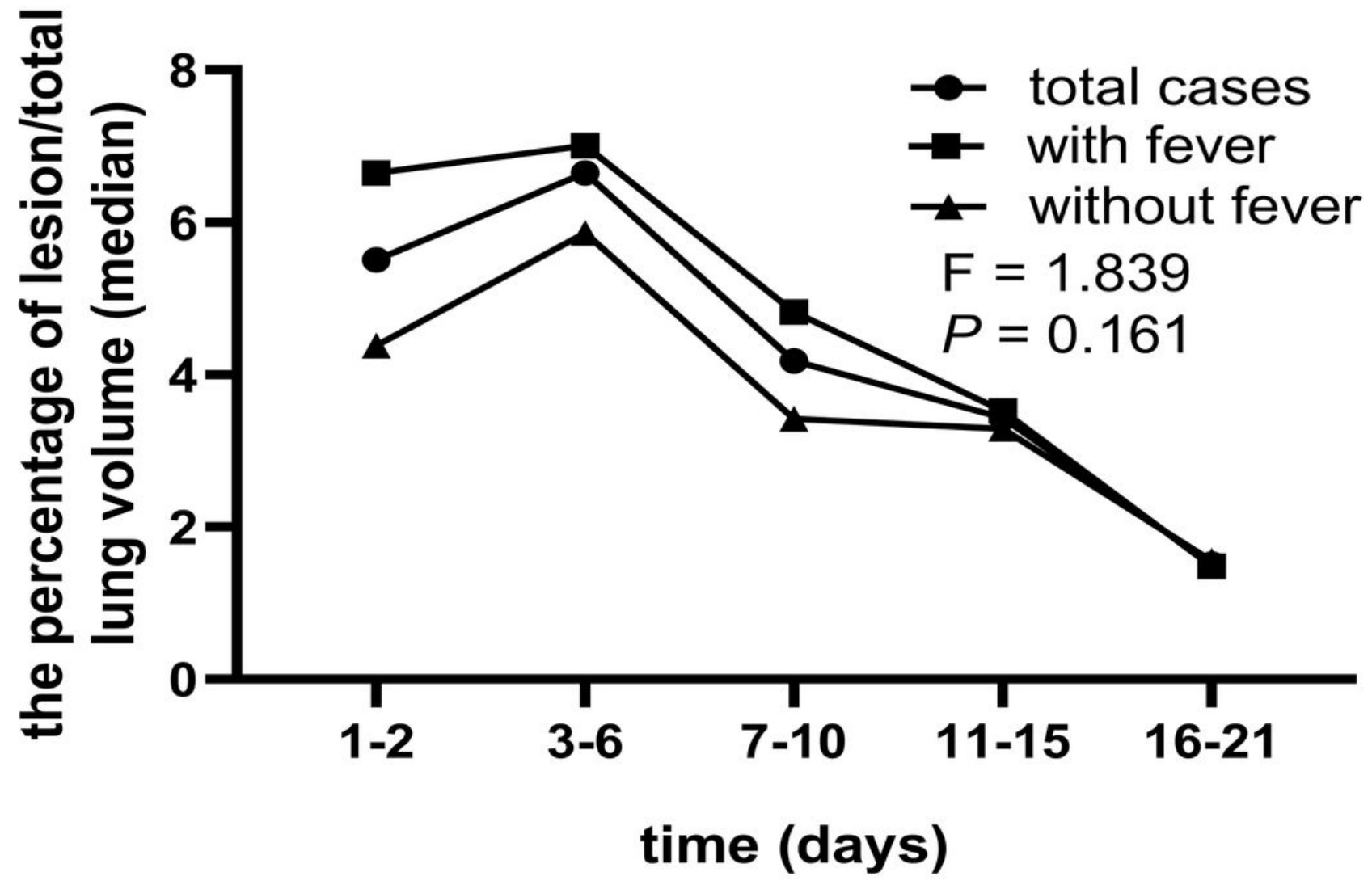

Figure 3

Comparison of the change trend of the percentage of lesion/total lung volume (y-axis) at different time (x-axis) between subjects with and those without fever 


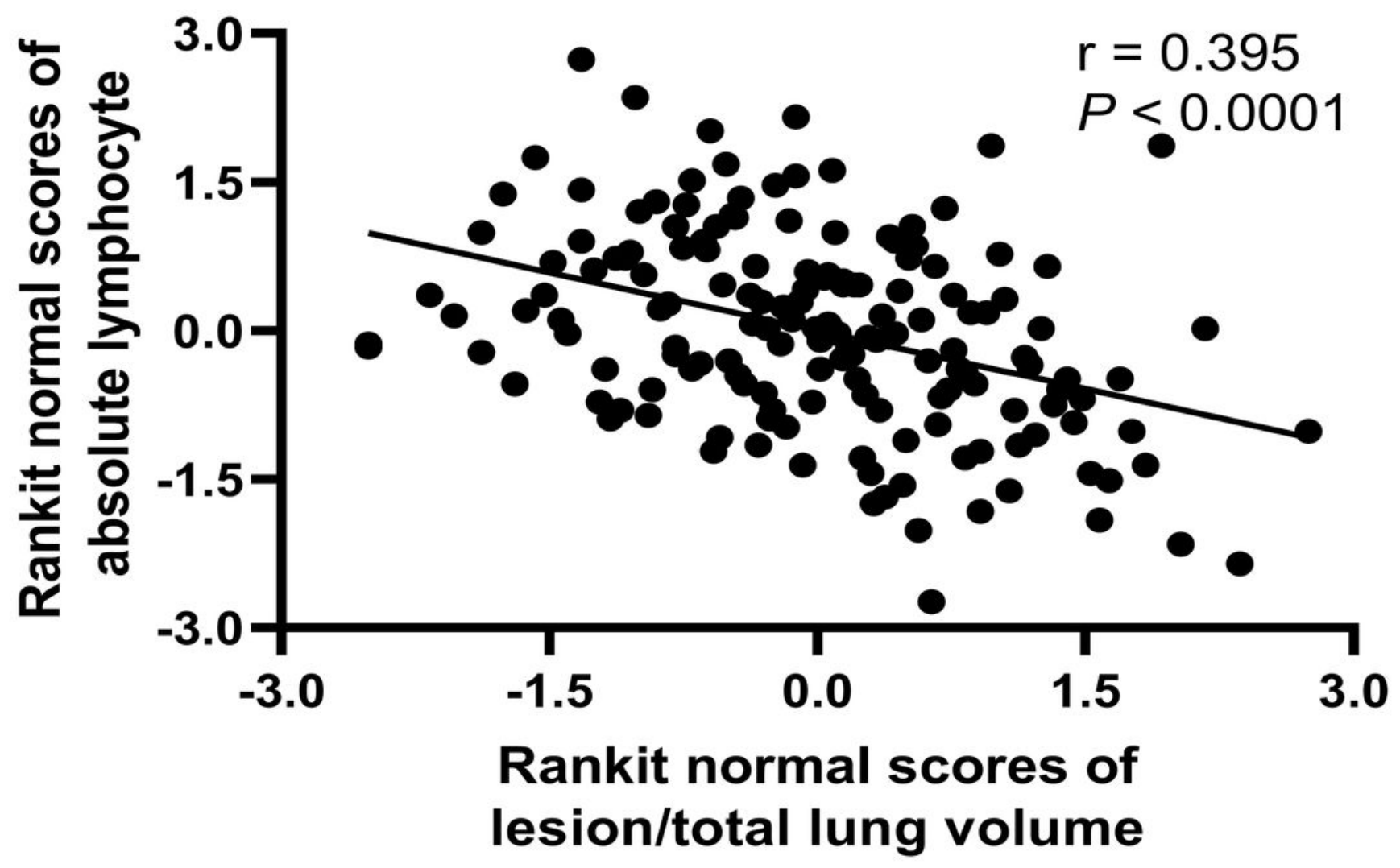

Figure 4

Scatter plot of the percentage of lesion/total lung volume (x-axis) and lymphocyte count in peripheral blood (y-axis). Linear correlation analysis showed a decrease trend of lymphocyte count in peripheral blood with the increase of percentage ratio 


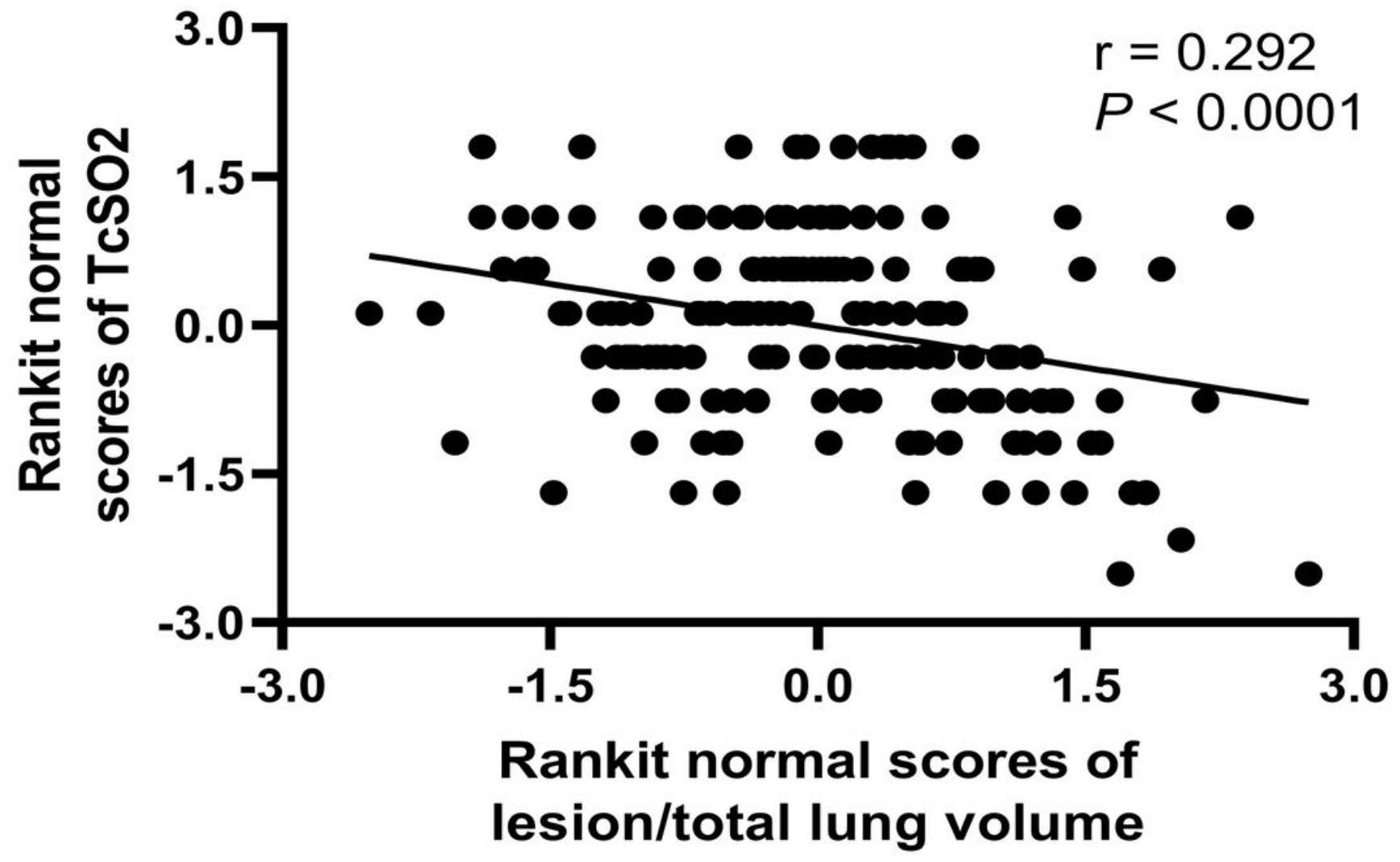

Figure 5

Scatter plot of the percentage of lesion/total lung volume (x-axis) and transcutaneous finger pulse oxygen saturation (y-axis). Linear correlation analysis showed a decrease trend of transcutaneous finger pulse oxygen saturation with the increase of percentage ratio 


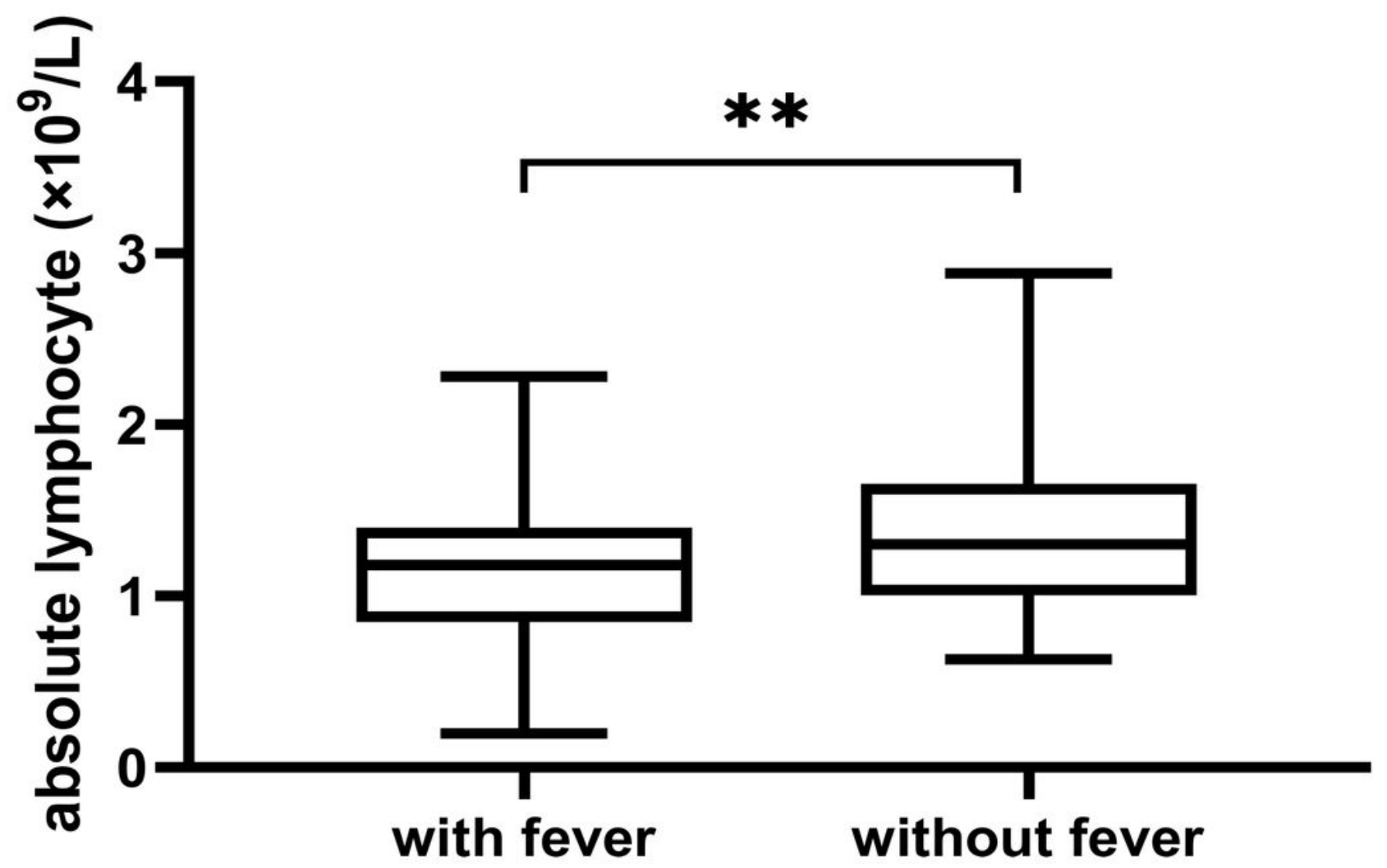

Figure 6

Box-plot of absolute lymphocyte distribution comparing subjects with and those without fever present on CT. The horizontal black line in the box represents the median value, and the horizontal edge of the box represents the interquartile range. ${ }^{\star \star} \mathrm{P}<0.01$

\section{Supplementary Files}

This is a list of supplementary files associated with this preprint. Click to download.

- Additionalfile1.doc

- Additionalfile3.doc

- Additionalfile2.doc 